
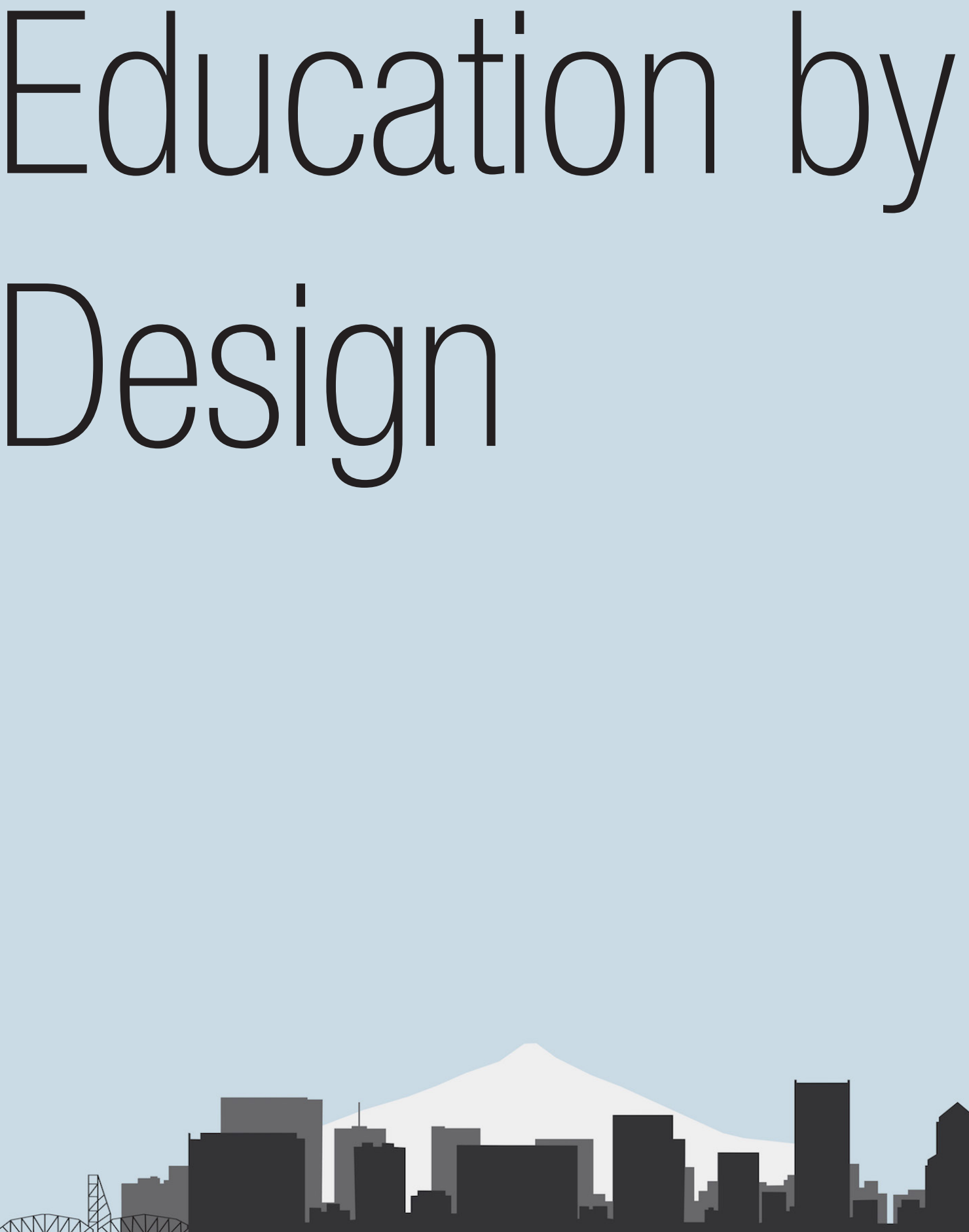

2019 Reynolds Symposium: Education by Design October 18-20, 2019 


\section{Organizing Committee:}

[co-organizers]

Professor Alison Kwok, Ph.D, FAIA, University of Oregon

Emeritus Professor John Reynolds, FAIA, University of Oregon

\section{[Symposium coordinator]}

Isabel Rivera, Ph.D., University of Oregon

Professor Walter Grondzik, P.E., Ball State University

Professor Bruce Haglund, AIA Assoc., University of Idaho

Assistant Professor Emily McGlohn, AIA, Auburn University

Associate Professor Ulrike Passe, lowa State University

Assistant Professor Siobhan Rockcastle, Ph.D., University of Oregon

Sharon Refvem, FAIA, LEED Fellow, Senior Associate and Director, Sustainability Resource Group, Hawley Peterson Snyder 


\title{
Educating Design Leaders: The Need for Leadership Education in Schools of Architecture And Proposed Approaches to Meet the Need
}

\author{
Erik Bonnett, NCARB \\ Assistant Teaching Professor \\ Montana State University \\ Bozeman, Montana \\ erik.bonnett@montana.edu
}

\begin{abstract}
There is a gap in architectural education when preparing future architects for leadership roles. To meet the needs of integrated design processes that frequently situate architects in leadership roles within interdisciplinary teams, more structured, comprehensive, and robust leadership education is needed. Fortunately, experiential leadership education can be effectively integrated into the dominant projectbased structure of architectural education using an iterative approach including strategic instruction, structured feedback, and reflection. Specific gaps in leadership education are identified including: student awareness of current leadership education, competence leading in multiple roles, goal setting and management as a leadership skill, judgement and decision-making, and knowledge of contemporary leadership theory. Strategies and curricula are proposed to support educators seeking to increase the effectiveness of leadership education in their classrooms, studios, and schools of architecture.
\end{abstract}

\section{INTRODUCTION}

In academic and professional literature as well as informal conversation it is recognized that practicing architects, and designers more broadly, play leadership roles (Gallant 2014; Posada 2007, 17; O'Donnell 2017; Morris 2019). Many firms position themselves as a "leader" in a specific area of architecture or design. Many architectural contracts codify the architect's role as the designated leader of a design team (AIA 2017). Within multi-person firms, architects and designers work in team structures, which necessitates leadership roles to be filled.

However, the following evidence suggests there is generally a gap in architectural education in terms of preparing future architects to succeed in leadership roles. The 2014 National Architectural Accrediting Board (NAAB) Student Performance Criteria do not include the word "leadership" or any significant expectation for students to learn leadership skills or knowledge (NAAB 2014). The Defining Perspectives section of the Conditions for Accreditation does include a minimal requirement for architecture schools to provide optional "opportunities for leadership roles." The related concept of "management" is included in the Student Performance Criteria, primarily in the context of project management, which encompasses only a small subset of leadership skills. Project and practice management is also encompassed in the Architectural Experience Program Guidelines, but a broader and more thorough approach to leadership is also scantly represented (NCARB 2019). For instance, the word "leadership" only appears in the following subset outcome under Practice Management: "Develop professional and leadership skills within firm." Similarly, the word "leadership" does not appear in the context discussed here in the Architect Registration Examination Handbook, though project and practice management are similarly included. And lastly, while current Architect Registration Examination questions are not available for analysis, the author did not encounter questions focused on leadership skills or knowledge in exams taken in 20162018, with the exception of contractual and ethical questions. Taken together, these standards suggests that in school students should have the option to gain experience in leadership roles, then as interns they are expected to acquire some unspecified leadership skills, but then are not subsequently assessed on their knowledge or skills during their registration examination. These standards do not seem to promote a comprehensive, coherent, or effective approach to leadership development. 
Of course, project management does include some key leadership skills. Also, many schools of architecture do provide students with more robust leadership education than the required minimum of an opportunity for leadership. Though consider for a moment if these standards were describing design thinking, not leadership. Imagine the uproar at faculty meetings nationwide if the new NAAB criteria only required "opportunities for design thinking" in lieu of the current robust and carefully structured curricular requirements. Developing design thinking is irrefutably a core outcome of architectural education, as I argue should be leadership development.

Recent graduates often lead teams of consultants within a few years of graduation. Shortly thereafter they will be leading teams within their firm. Hopefully they will play leadership roles within professional organizations or in their communities. One day they may own their own firm or be a principal. At least some in the AIA recognize the gap in leadership development, such as a concession on their website that "when people reach that point as a senior leader in their firm, it doesn't mean that they had addressed the people management issues of practice management" (O'Donnell 2017). Furthermore, leadership development research indicates that leadership performance is not correlated with job experience (Day et al. 2014, 64-66). So when are architects to learn about leadership? Solely through mentorship? It is doubtful our colleagues over at the business school would advocate a mentorship-only leadership development pedagogy. Architecture schools have the opportunity to play a much larger, more focused, and more effective role in preparing graduates for the leadership roles in their future.

Additionally, the ways in which the profession is changing demand higher-quality and more leadership from architects. Many design teams now consist of a large group of specialized consultants, ranging from the engineers to specialized consultants, and even scientists and policy advocates. Additionally, some specialists, such as waterproofing consultants, perform a scope that used to be the sole responsibility of architects. With the increasing scope handled by specialized consultants, the role of the architect is increasingly to coordinate and lead the team. This is especially evident with integrated and highperformance design teams, who often use charrettes to create innovative interdisciplinary design solutions. In many instances, architects are the designated leader of integrated design teams. In other instances, another entity may be the designated leader, but architects can and should contribute to team performance in what is referred to as peer, distributed, or horizontal leadership roles, as well as supporting the designated leader as an active follower (Posada 2007, 17; Bouwmans et al. 2019). Research looking at the structure of student and professional architecture, engineering, and construction teams indicates that barriers between team members leads to reduced collaboration and lower team performance, while both distributed and designated leadership plays a key role in facilitating high team performance (Korkmaz and Singh 2012).

In integrated design processes, especially when performing the role of a designated leader, an architect's ability to lead and facilitate is as, if not more, important than their design thinking ability. Research looking at interdisciplinary collaboration indicates the paramount importance of facilitative leadership, which is a leadership model focused on group involvement in decision-making and the formative impact of building relationships on high team performance (Edelenbos, Bressers, and Vandenbussche 2017; Smith 2003). Furthermore, this research suggests that effective facilitative leadership is especially important and challenging at the end of a project, when time pressures push members to revert to conventional (siloed) work processes (Edelenbos, Bressers, and Vandenbussche 2017, 462). In a designated or peer/distributed leadership role in an integrated design team, an architect's ability to facilitate innovation and catalyze the formation of a high-performance team is essential for the design team to reach its full potential, and therein for them to create the highest performing building.

Though interdisciplinary collaboration research asserts the importance of effective leadership in integrated design teams, educational texts such as Keeler and Burke's Fundamentals of Integrated Design for Sustainable Building and Kwok and Grondzik's The Green Studio Handbook, scarcely mention leadership and team dynamics (Keeler and Burke 2009, Kwok and Grondzik 2007). Keeler and Burke mention the need to clearly define roles in integrated design teams, but little is discussed of how to lead or facilitate effective collaboration once roles are defined (Keeler and Burke 2009, 3). David Posada, writing in Green Studio, alludes in one sentence to the need for design leadership in integrated teams and suggests this leadership requires different skills and competencies, than the centralized leadership characteristic of conventional design processes (Posada 2007, 17). While interdisciplinary collaboration 
research suggests that team performance is about more than just bringing the right people and ideas together, there appears to be a lack of strategies, theory, and instruction on effective interdisciplinary team leadership in prominent integrated design educational texts. Therefore, increasing leadership education for architects participating in integrated design appears to be a critical component of efforts to meet the goals of integrated design, including addressing the climate and environmental crises, and specifically the movement to meet the 2030 Challenge (Architecture 2030 2019).

To meet this need for high-quality leadership in practice, I argue that schools must do more than provide "opportunities for leadership roles." They would serve their students well by implementing a focused experiential leadership curriculum, including developing competence in specific applicable skills and building knowledge of current conceptual frameworks and theory, applied in iterative leadership experiences for practice and development.

\section{PEDAGOGY AND CURRICULUM}

Leadership is taught in many other disciplines in higher education, especially professional degree programs, including business, public administration, even dentistry (Revell 2008; Taichman et al. 2012). Curricula often focus on a combination of theory and skills, while pedagogy often seeks to provide leadership practice to students. This is sometimes accomplished with discussion of case studies or with role-playing scenarios (Revell 2008). Research looking at the development of leadership ability, suggests that leadership is developed over time and is less about receiving the right curricula in trainings and more about an iterative process of experience, reflection, and new information (Day et al. 2014, 67, 80). In other words, leadership development happens in the white space between instruction (Day et al. 2014, 80). Thus, architectural education is well-positioned to implement a more robust leadership pedagogy because it is already structured around projects that are crafted to simulate the professional environment and is already an iterative cycle of acquiring and applying new knowledge and skills. Thus, an integrated tripartite approach is proposed herein for leadership education in schools of architecture: skills, theory, and practice.

There are many models and definitions of leadership in the literature on the topic. For instance, Fryer (somewhat ironically), suggests that "leadership is basically doing what the leader wants" (Fryer 2011, 26). An AIA article on leadership includes definitions such as "be the change you want to see," and "learning how to apply your voice in an authentic way to create change in the world" (O'Donnell 2017). The outdoor leadership education forerunner, NOLS, uses an iterative experiential learning process similar to what could be implemented in an educational architecture studio. They define leadership as "situationally appropriate action that directs or guides a group to set and achieve goals" (Gookin and Leach 2009, 10). The body of literature on leadership includes numerous models such as transactional leadership (carrot and stick), hybrid leadership (combining designated and distributed leadership), facilitative leadership (group decision-making involvement), transformational leadership (motivating and inspiring change), leadership development theory (it is how ability is developed over time that matters), and authentic leadership (a values-based connection between leaders and the group) (Banks et al. 2016; Bouwmans et al. 2019; Day et al. 2014; Fehr 2017; Smith 2003).

This paper does not attempt to propose a new model or definition of leadership. Instead it proposes a more robust application of curricula and pedagogy developed in other fields to architectural education. In this context, this paper focuses on leadership as a set of skills and abilities that can be learned and applied by groups and individuals in a group setting. Lastly, this kind of leadership should be distinguished from leadership as a near synonym for innovation, as the term is commonly used in reference to award-winning design and Leadership in Energy and Environmental Design (LEED). 
Table 1. Author's Assessment of Frequency of Leadership Skills Incorporation into Architectural Education

\begin{tabular}{|c|c|c|}
\hline Common & Partial* & Uncommon \\
\hline $\begin{array}{l}\text { - Competence } \\
\text { - Communication } \\
\text { - Tolerance for Adversity } \\
\text { and Uncertainty }\end{array}$ & $\begin{array}{l}\text { - Self-Awareness } \\
\text { - Vision and Action } \\
\text { - Attitude and Mindset }\end{array}$ & $\begin{array}{l}\text { - Judgement and Decision- } \\
\text { Making } \\
\text { - Ability in Varied Roles }\end{array}$ \\
\hline
\end{tabular}

*Often incorporated on the individual level, but not in the team context or as a leadership skill.

There are components of leadership education which are already incorporated in architectural education. Based on the author's experience in schools of architecture as a faculty member and student, the following are likely a component of most architectural educations: developing competence, communication skills, and tolerance for adversity and uncertainty. However, many students may not recognize these as leadership skills. Specifically with competence, many students may falsely believe that leadership requires preeminent competence, which would limit their willingness to take on leadership and their perceived ability in leadership roles. To some extent the following set of leadership skills are a component of architectural education currently: self-awareness, vision and action, and attitude/mindset. However, in many cases, these skills are focused on the individual student rather than on leadership (e.g. selfawareness around representational strengths as opposed to self-awareness around decision-making facilitation skills). There are additional important leadership skills, which in the author's experience are largely absent from architectural education, including judgement and decision-making and an ability to lead effectively in a variety of leadership roles.

The following are specific strategies aimed to support architectural educators attempting to bolster the quality, depth, and effectiveness of leadership education in their teaching.

\section{DEBRIEFS AND REFLECTION}

Making the transition from providing "opportunities for leadership roles" to providing robust leadership education is in many ways about what happens before and after leadership opportunities (Day et al. 2014, 67,80 ). The following chart is an iterative model of leadership learning. The first step consists of identifying an upcoming leadership opportunity and providing relevant and applicable knowledge that the student can apply during the leadership opportunity. Second, leadership opportunities should be structured to provide hands-on experience applying new knowledge and skills, continuing to build competence in other dimensions of leadership. Following the experience, self, peer, and instructor feedback, known as 360 degree feedback, will maximize the student's raw material for potential growth (Day et al. 2014, 70-72). Finally, structured reflection allows the student to process, consolidate, and internalize the experience, feedback, and learning. This process allows educators to structure otherwise isolated leadership experiences into a developmental progression infused with strategic relevant instruction to catalyze leadership development.

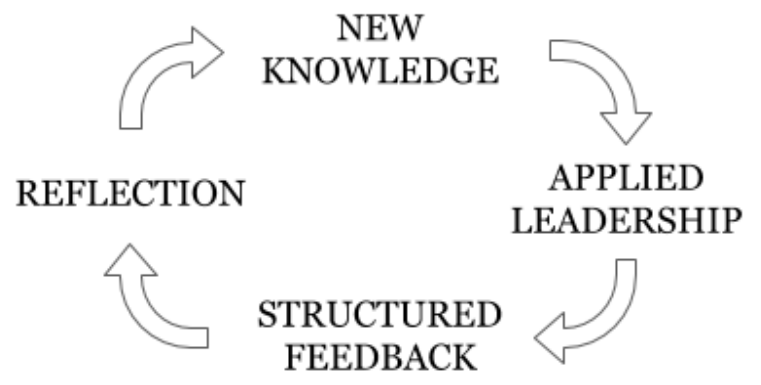

Figure 1. Cycle diagraming the proposed iterative model of the leadership learning process. 
A specific example of reflection being used in an architectural education context is a Chinowsky et al.'s use of Social Network Analysis (SNA) to map an interdisciplinary student team competing in an energyefficient housing competition (Korkmaz and Singh 2012, 294). SNA is a method to mathematically visualize and understand a team's dynamics (Korkmaz and Singh 2012, 289). High performance interdisciplinary teams have more robust and interconnected networks: the opposite of "divide and conquer" (Korkmaz and Singh 2012, 290). Mapping a team's social network and reflecting it back to them can help them make modifications to become more effective.

Juroszek has used visualization in a similar way to facilitate reflection (Juroszek 2018). He created a visual spider chart (a circular graph like a wind rose) to map and visualize how students use their time (Juroszek 2018). The tool allows user-input axis labels and could be tailored specifically to visualize team dynamics and leadership, for instance by mapping a group's time spent working independently, meeting, reviewing others' work, communicating 1:1, and interacting with group members outside of project work.

More depth and specificity of discussion is also warranted on the use of debriefs to structure the feedback process. Most American architectural educations use reviews and/or critiques to structure feedback and reflection on design. Debriefs are a similar structure used to facilitate feedback and reflection on leadership (Revell 2008, 106). Debriefs are facilitated using targeted open-ended questions (e.g. what worked, what was challenging, what did you learn, etc.) to provoke student reflection and learning (Revell $2008,106)$. At the end of a leadership experience, for instance a group project, consider leading a debrief focused on group effectiveness and leadership. Structuring and conveying intention for leadership growth, followed by debrief and reflection can augment group projects and other leadership opportunities to achieve specific leadership learning outcomes.

\section{LEADERSHIP ROLES}

In the author's experience teaching leadership to university students, adults, and members of the armed services, leadership is often conflated with Designated Leadership. In fact, leadership can be thought of to include several roles in addition to Designated Leadership, i.e. those who derive their leadership authority from a defined leadership position or role (deans, principles, presidents, etc.). Leadership also includes leadership of self, without which an individual levies a net deficit on the performance of a team, and Active Followership which includes leadership actions taken by members of a team to support team goals (Gookin and Leach 2009, 11). And there is also Peer, Distributed, or Horizontal Leadership, which is the challenging task of providing leadership from a horizontal position within a group (Gookin and Leach 2009, 11; Vocation).

Frequently in core classes and studios students are assigned groups or self-select groups, then are tasked with completing a project with little or no group structure. This is placing students in a Peer Leadership position. If you have ever heard your students groan when a group project is assigned, their reaction may very well be reasonable apprehension to be placed into a very difficult leadership situation (Peer Leadership) for which they probably have had little or no instruction or training. However, psychology and education research suggests that there are significant benefits to group work in terms of educational outcomes (Naidoo 2017). Though in professional practice teams almost always are created with some kind of leadership structure, such as a designated leader, in schools assigning designated leaders is quite rare. Next time you assign a group project, consider teaching your students about various leadership roles. Perhaps assign team leaders on a rotation so each student can experience leadership in a variety of roles that are more relevant to their probable experience in practice. If you feel a horizontal Peer Leadership structure is important, consider supplementing the project with instruction on applicable decisionmaking styles (see the following page).

The relationship and impact of leadership in various roles was well explored in a Michigan State University interdisciplinary studio that included construction management, urban planning, interior design, and landscape architecture (Korkmaz and Singh 2012, 290). Korkmaz and Singh carefully analyzed team dynamics, communication patterns, and performance of the student groups and found that the higher performing groups had either robust peer/distributed leadership or a peer-leader who rose to an informally designated role (Korkmaz and Singh 2012, 292-93). Unfortunately, the researchers 
concluded that prescreening should be implement in group work to distribute students with stronger leadership abilities among groups (Korkmaz and Singh 2012, 293-94). Alternatively, this study could be viewed from the lens of leadership development (leadership aptitude is not innate but is developed over time) as opposed to a fixed mindset approach. Then the studio can be seen as a highly commendable interdisciplinary learning experience, and could provide a rich environment for development of facilitative leadership skills in both designated and peer roles, especially with leadership instruction and coaching.

\section{GOAL SETTING AND MANAGEMENT}

The authentic and transformational leadership models, both prominent in contemporary leadership research, focus on the interpersonal connection between leader and group (Banks et al. 2016). The National Outdoor Leadership School defines leadership by specifically connecting the leader and group through goal setting and achievement (NOLS 2019). Even a transactional leadership model can be seen as using incentives and punishment to achieve goals (Banks et al. 2016). Across these and other leadership models, goal setting and management is a core component of leadership.

Consider incorporating goal setting into your class as a leadership skill. The SMART framework for goal setting has proven useful and effective for the many groups and organizations as well as this author (Specific, Measurable, Attainable, Relevant, Timely) (Leach 2009, 53). To more robustly teach goal setting as a leadership skill, teach and assign it as a component of a group project to be completed at least in part by the group.

\section{JUDGEMENT AND DECISION MAKING}

One of the key skills aiding effective leaders, especially in Peer/Distributed Leadership roles, is an understanding of and competence in a variety of decision-making styles. Lacking an understanding of how to effectively structure appropriate decision-making processes compounds the challenges students face when placed in unstructured teams for group projects. Furthermore, facilitative leadership, which is critical to integrated design teams, is highly focused on effective decision facilitation to build group capacity and maximize performance (Edelenbos, Bressers, and Vandenbussche 2017, 462).

As depicted below, various decision-making styles can be understood as existing on a plane where one axis represents the time taken to make a decision, while the other axis represents both the probable quality of a decision reached and the buy-in/investment the team will feel in the decision. This framework helps students understand that various ways of making decisions are not interchangeable but have an impact on important dimensions of the team. Consider teaching students multiple decision-making styles as part of a group project and challenging teams to employ each style at least once over the course of the project. 


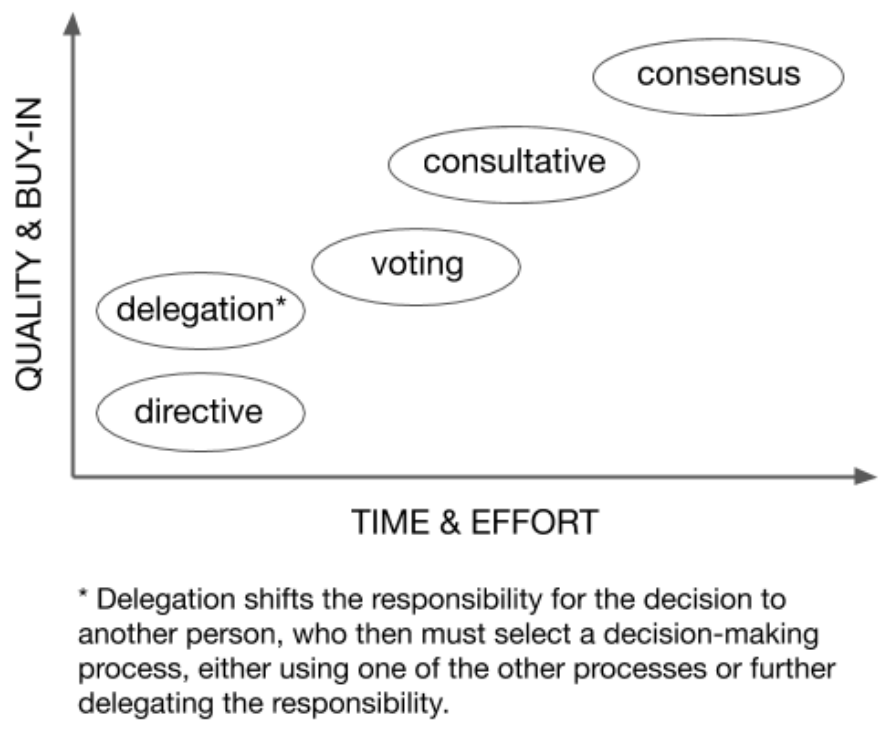

Figure 2. Decision-making styles: the process used to make a decision impacts not only the deliberation time, but also the quality of the outcome of the decision and team investment and buy-in in the outcome. Decision-making itself is a powerful tool to help build a highfunctioning team, but implemented poorly can also lead to low team performance long after the decision has been reached. (Adapted from Gookin and Leach 2009, 34).

\section{INDIVIDUAL STYLE}

While this paper takes the position that there are universally important learnable leadership skills, it is also undeniable that each individual will approach leadership by building on their unique strengths. There are many tools available to help explore individual differences, strengths, and areas of growth. These tools can be an excellent way to structure a debrief. The author suggests the No-Doze four-quadrant model for leadership, which encourages students to reflect on their innate aptitudes, how their aptitudes may align with others creating resonance or challenge, and how a leader's aptitudes and abilities develop as they mature as a leader (Doran 2009, 48). Research on personality traits and leadership has not conclusively demonstrated that certain traits are necessary as a prerequisite for leadership (Day et al. 2014, 64, 79). Thus the author suggests emphasizing specific strengths, weaknesses, and areas for growth related to specific traits while minimizing relative comparisons between them.

\section{LEADERSHIP THEORY}

Case studies for innovative leadership are far more often focused on tech companies than architecture firms. Exposing architecture students to contemporary and innovative management ideas can help improve firm leadership and performance and help prepare students for a variety of leadership roles. For instance, an understanding of the components of facilitative leadership will help students understand the dynamics of leading interdisciplinary teams, such as balancing advocacy and inquiry (contributing and active listening) (Smith 2003). There is also a significant body of research in leadership development indicating the importance of a growth (learning) mindset as opposed to a fixed mindset (Dweck 2014; Heslin and Keating 2017; Yeager and Dweck 2012). Understanding this will help students learn from leadership opportunities and develop more quickly as leaders. Furthermore understanding characteristics of authentic and transformation leadership, especially compared to transactional leadership models can help them understand leadership models they experience and create more effective team dynamics (Banks et al. 2016). 
That said, concentrated leadership trainings don't have a large impact on leadership development; to be effective, leadership experiences, skills, and knowledge must be gained at appropriate times in a leader's development (25 years). In other words, think of leadership theory instruction more as desk critiques and nuggets than a lecture or unit.

\section{CONCLUSION}

Like design, effective leadership requires a combination of knowledge and skills which must be learned in large part by doing. Some important leadership skills are already taught in most American architecture schools. But to meet the needs of integrated design processes that increasingly situate architects in leadership roles within interdisciplinary teams, more structured, comprehensive, and robust leadership education is needed. This paper has asserted that experiential leadership education can be effectively integrated into the project-based structure of architectural education using an iterative approach consisting of targeted instruction in leadership knowledge, leadership practice, then by feedback and reflection. Specific gaps in current leadership development strategies in architectural education include student awareness of current leadership education, competence leading in multiple roles, goal setting and management as a leadership skill, judgement and decision-making, and knowledge of contemporary leadership theory. The proposed strategies, curricula, and ideas have been used by the author and colleagues to support leadership growth in the areas identified. The aim is to support educators seeking to increase the effectiveness of leadership education in their classrooms, studios, and schools of architecture. As strong, competent, and knowledgeable leaders, graduates will be better prepared for an evolving profession and more capable of meeting the challenges posed by the climate crisis.

\section{REFERENCES}

American Institute of Architects (AIA). Document B1O1 - 2017: Standard Form of Agreement Between Owner and Architect. 2017. http://content.aia.org/sites/default/files/201704/B101_2017\%20sample.pdf (Accessed June 28, 2019).

Architecture 2030. 2019. “The 2030 Challenge”. Accessed August 15. https://architecture2030.org/2030_challenges/2030-challenge/

Banks, George C., Kelly Davis McCauley, William L. Gardner, and Courtney E. Guler. 2016. “A MetaAnalytic Review of Authentic and Transformational Leadership: A Test for Redundancy.” The Leadership Quarterly. Vol. 27: 634-652.

Bouwmans, Machiel, Piety Runhaar, Renate Wesselink and Martin Mulder. 2019. "Towards Distributed Leadership in Vocational Education and Training Schools: The Interplay Between Formal Leaders and Team Members." Educational Management Administration and Leadership. Vol. 47(4): 555-571.

Day, David V., John W. Fleenor, Leanne E. Atwater, Rachel E. Sturm, and Rob A. McKee. "Advances in Leader and Leadership Development: A Review of 25 Years of Research Theory." Leadership Quarterly Vol. 25 (2014): 63-82.

Doran, Molly. 2009. “The No-Doze Leadership Styles Class." in 2009 NOLS Leadership Educator Notebook: A Toolbox for Leadership Educators, ed. by John Gookin and Shari Leach. Lander: National Outdoor Leadership School,.

Dweck, Carol. 2014. "How Companies Can Profit From a Growth Mindset." Harvard Business Review. Vol. November 2014: 28-29.

Edelenbos, Jurian, Nanny Bressers, and Lieselot Vandenbussche. 2017. "Evolution of interdisciplinary collaboration: what are stimulating conditions?" Science and Public Policy. Vol. 44(4): 451-463. 
Fehr, Ryan, Ashley Fulmer, Eli Awtrey, and Jared A. Miller. 2017. “The Grateful Workplace: A Multilevel Model of Gratitude in Organizations.” Academy of Management Review. Vol. 42(2): 361-381.

Fryer, Mick. 2011. "Facilitative leadership: drawing on Jürgen Habermas' model of ideal speech to propose a less impositional way to lead." Organization. Vol. 19(1): 25-43.

Gallant, Pierre. 2014. “Architecture Matters: Architecture Requires Leadership Skills.” Journal of Commerce 79: 1-2.

Gookin, John and Shari Leach. 2009. 2009 NOLS Leadership Educator Notebook: A Toolbox for Leadership Educators. Lander: National Outdoor Leadership School.

Heslin, Peter A. and Lauren A. Keating. 2017. "In learning mode? The role ofmindsets in derailing and enabling experiential leadership development.” The Leadership Quarterly. Vol. 28: 367-384.

Juroszek, Steven P. 2018. “Unit of Measurement 2: Measuring Time.” Journal of the Design Communication Association. Vol. 2017-2018: 112-119.

Keeler, Marian and Bill Burke. 2009. Fundamentals of Integrated Design for Sustainable Building. Hoboken, NJ: John Wiley and Sons, Inc.

Korkmaz, Sinem and Aditya Singh. 2012. "Impact of Team Characteristics in Learning Sustainable Built Environment Practices.” Journal Of Professional Issues In Engineering Education \& Practice. October 2012: 289-295.

Kwok, Alison G., and Walter T. Grondzik. 2007. The Green Studio Handbook: Environmental Strategies for Schematic Design. Oxford: Architectural Press.

Leach, Shari. “S.M.A.R.T. Goal Setting." 2009. in 2009 NOLS Leadership Educator Notebook: A Toolbox for Leadership Educators, ed. by John Gookin and Shari Leach. Lander: National Outdoor Leadership School.

Morris, Neal. 2019. "Leadership Skills Every Architect Should Learn.” Accessed August 15. https://www.architecture.com/knowledge-and-resources/knowledge-landing-page/leadership-skillsevery-architect-should-learn.

Naidoo, Loren J. 2017. “Max. Classroom Capacity: The Dreaded Group Project.” The IndustrialOrganizational Psychologist. Vol. 55(2).

National Architectural Accrediting Board (NAAB). 2014 Conditions for Accreditation. Washington, DC: 2014. https://www.naab.org/wp-content/uploads/o1_Final-Approved-2014-NAAB-Conditions-forAccreditation-2.pdf (Accessed June 24, 2019).

National Council of Architectural Registration Boards (NCARB). Architectural Experience Program Guidelines. 2019. https://www.ncarb.org/sites/default/files/AXP-Guidelines.pdf (Accessed June 24, 2019).

National Outdoor Leadership School (NOLS). n.d. “Curriculum.” Accessed June 24, 2019. https://www.nols.edu/en/resources/curriculum/.

O’Donnell, Kathleen M. 2017. "Architects Define Leadership for a Changing Profession.” Accessed August 15. https://www.aia.org/articles/165456-architects-define-leadership-for-a-changing. 
Posada, David. 2007. “Integrated Design.” in The Green Studio Handbook: Environmental Strategies for Schematic Design, ed. by Alison G. Kwok and Walter T. Grondzik, 15-20. Oxford: Architectural Press.

Revell, Keith. “Leadership Cannot Be Taught.” Journal of Public Affairs Education Vol. 14, No. 1 (2008): 91-110.

Smith, Alisdair. 2003. "Facilitative Leadership.” Accessed August 15. https://www.grad.ubc.ca/currentstudents/professional-development/facilitative-leadership.

Taichman, Russell S., Joseph W. Parkinson, Bonnie A. Nelson, Barbara Nordquist, Daphne C. FergusonYoung, and Joseph F. Thompson. 2012. "Leadership Training for Oral Health Professionals: A Call to Action.” Journal of Dental Education. Vol. 76(2): 185-191.

Yeager, David Scott and Carol S. Dweck. 2012. "Mindsets That Promote Resilience: When Students Believe That Personal Characteristics Can Be Developed." Educational Psychologist. Vol. 47(4): 302314 . 